\title{
Development of an automatic arc welding system using an adaptive sliding mode control
}

\author{
Cheng-Yu Wu • Pi-Cheng Tung • Chyun-Chau Fuh
}

Received: 13 March 2008 / Accepted: 3 September 2008 / Published online: 27 November 2008

(C) The Author(s) 2008. This article is published with open access at Springerlink.com

\begin{abstract}
This paper develops an automatic welding control scheme for alternating current shielded metal arc welding (SMAW) system. A mathematical model of the welding control system is derived and the system parameters identified. An adaptive sliding mode controller is designed to estimate the bound of the system uncertainties and to modulate the electrode feed rate in such a way that the desired arc length and arc current are maintained as the electrode melts during the welding process. The proposed control method is suitable for any consumed electrode welding technique. The simulation and experimental results show that the automatic welding control system successfully maintains the magnitude of the arc current at the desired value and preserves the arc stability, thereby obtaining an enhanced SMAW control system performance.
\end{abstract}

Keywords Shielded metal arc welding - Variable structure control $\cdot$ Adaptive sliding mode $\cdot$ Sliding surface

\section{Nomenclature \\ a Viscous damping coefficient of welding system \\ $e_{i} \quad$ Error signal between actual and desired output variable}

C.-Y. Wu · P.-C. Tung $(\varangle)$

Department of Mechanical Engineering, National Central

University, Chung-Li 320, Taiwan

e-mail: t331166@ncu.edu.tw

C.-Y. Wu

e-mail: 93343016@cc.ncu.edu.tw

C.-C. Fuh

Department of Mechanical \& Mechatronic Engineering, National

Taiwan Ocean University, Keelung 20224, Taiwan

e-mail: f0005@mail.ntou.edu.tw

\begin{tabular}{|c|c|}
\hline$y$ & Actual output variable \\
\hline A & State gain matrix \\
\hline$B$ & Input gain matrix \\
\hline$C$ & Output gain matrix \\
\hline$\alpha$ & Adaptive gain \\
\hline$\lambda$ & Slope of the sliding surface \\
\hline$\dot{e}$ & $\begin{array}{l}\text { Derivative error between actual and desired } \\
\text { output variable }\end{array}$ \\
\hline $\bar{e}$ & Bound of the disturbance \\
\hline $\bar{\beta}$ & Upper bound of the disturbance \\
\hline$k_{\mathrm{mr}}$ & Coefficient ratio of melting rate to arc current \\
\hline$k_{v}$ & $\begin{array}{l}\text { Coefficient ratio of melting rate to the arc } \\
\text { voltage }\end{array}$ \\
\hline$K_{m}$ & Motor constant \\
\hline$u_{\text {eq }}$ & $\begin{array}{l}\text { Equivalent control of the sliding mode } \\
\text { controller }\end{array}$ \\
\hline$T_{\mathrm{d}}$ & Disturbance \\
\hline$v_{\mathrm{fr}}$ & Electrode feed-rate \\
\hline$v_{\mathrm{mr}}$ & Electrode multing-rate \\
\hline$V_{\mathrm{a}}$ & Arc voltage \\
\hline$s(t)$ & Sliding surface \\
\hline sat $(s)$ & Saturation function \\
\hline$E(s)$ & $\begin{array}{l}\text { Error signal between reference input, } I_{\mathrm{r}}(s), \\
\text { and welding current, } I_{\mathrm{a}}\end{array}$ \\
\hline$G(s)$ & Transfer function of the welding control system \\
\hline$H(s)$ & Current sensor of the welding control system \\
\hline$V(s)$ & Output signal of the controller \\
\hline$I_{\mathrm{a}}(s)$ & $\begin{array}{l}\text { Transfer function of arc current, } I_{\mathrm{a}} \text {, in welding } \\
\text { control system }\end{array}$ \\
\hline$I_{\mathrm{r}}(s)$ & $\begin{array}{l}\text { Transfer function of reference input to welding } \\
\text { control system }\end{array}$ \\
\hline$V_{\mathrm{f}}(s)$ & Transfer function of electrode feed rate \\
\hline
\end{tabular}




\section{Introduction}

Welding processes are widely used throughout industry to perform a range of fabrication tasks. Of the various welding techniques available, stick-electrode welding, more formally known as shielded metal arc welding (SMAW) is one of the most common. Faced with rising labor costs, many manufacturers are moving towards process automation in an attemp$t$ to reduce their costs and increase productivity. However, the manual SMAW process still accounts for the majority of the total welding filler-metal business since it provides an exceptional versatility, low equipment costs, convenient power source requirements, low maintenance costs, durability, a relatively straightforward operation, and a simple set-up (Smith 1989). SMAW is a consumed electrode welding technique, i.e. the electrode not only supplies the fillermetal, but also acts as the consumable material. Therefore, the electrode feed rate must be carefully controlled during the welding process to ensure that the arc length remains constant. Hence, SMAW is generally carried out manually by a skilled technician, despite the high labor cost which this incurs. Automatic welding systems not only contribute toward a long-term reduction in labor costs, but also ensure a unifor$\mathrm{m}$ welding performance. However, in developing such systems, many problems must be overcome, including achieving a stable ignition and ensuring a consistent welding result. In implementing a control system for SMAW, the main challenges include controlling the electrode feed rate and preserving the stability of the arc during the welding process.

It has been reported that the welding performance can be improved by implementing appropriate inverter control methods (Zhang et al. 1998; Lu et al. 2004; Zhang and Walcott 2006). Many such methods have been proposed, including the output-current slope control scheme and the pulsed output-current control method (Verdelho et al. 1998). However, since these control methods essentially ignore the welding problems associated with the metal transfer procedure itself, welding may be performed under sub-optimal conditions, leading to no more than a limited reduction in spatter generation (Yamamoto et al. 1990).

The welding performance can also be enhanced by implementing instantaneous output current and voltage controllers based on feedback current control schemes (Abdelrahman 1998; Chae et al. 1999; Baldwin et al. 2005; Modenesi and Reis 2007; Ngo et al. 2007). However, the implementation of such schemes in practical welding systems is challenging since they require the provision of an optimum output current reference waveform and a sophisticated adjustment of the current controller gain. All the paper referred to above have focused on research in the field of gas metal arc welding (GMAW) or gas tungsten arc welding (GTAW). Interestingly, although SMAW is widely used throughout industry, it has received comparatively little attention in the literature. In the
SMAW process, even a relatively minor variation in the arc length, e.g. a few $\mathrm{mm}$ to a few tens of $\mathrm{mm}$, is sufficient to create an enormous arc voltage fluctuation, leading potentially to melting of the weld, porosity, and undercutting of the adjacent base metal, etc. Hence, as discussed above, an automatic SMAW control system must be capable of stabilizing the arc length such that these voltage fluctuations are eliminated.

Sliding mode control (SMC), a form of variable structure control (VSC) (Shyu et al. 1992; Hung et al. 1993; Decarlo et al. 1998), utilizes a high-speed switching control to derive the state trajectory of a plant onto a specified surface in the state space, and to maintain the state trajectory on this surface for all subsequent time such that the stability of the system is assured. The benefit of designing a system through VSC is that when the system is in this sliding mode, its transient response can be prescribed in advance and is insensitive to variations in the plant parameters and external disturbance. Consequently, various researchers have employed the VSC method to construct model-following control systems (Spurgeon and Patton 1999). In recent decades, model-following control has emerged as a robust method for controlling a linear time-invariant plant with unknown parameters or uncertainties or robotic manipulators (Shyu and Liu 1996; Spurgeon and Patton 1999; Wang et al. 2001a, b; Chung et al. 2004; Abdelhameed 2005). In such approaches, a simple adaptive algorithm is used to estimate favorable small values rather than the conventional sliding mode control.

The objective of this study is to implement an automatic SMAW process. A mathematical model of the automatic welding system is constructed and suitable parameter values for the control system identified. An adaptive sliding mode controller is employed to estimate the upper bound of the system disturbances. The control scheme is designed to regulate the electrode feed rate such that the specified arc length, and hence arc current, are maintained as the electrode is consumed during the welding process.

\section{Dynamic system modeling}

In this study, the welding current is provided by a conventional $160 \mathrm{Amp}$ constant current AC power supply with a very steep current-output slope, as shown in Fig. 1. It is observed that the output current is essentially constant in the normal operating range. Although suitable for many welding processes, this constant current AC power supply is used primarily for flux-covered stick electrode (SMAW) since the welding performance of this technique is particularly dependent on maintaining a stable current. In the manual SMAW process, the desired welding current values are predetermined by the operator and are obtained by regulating the length of the arc between the electrode and the workpiece 


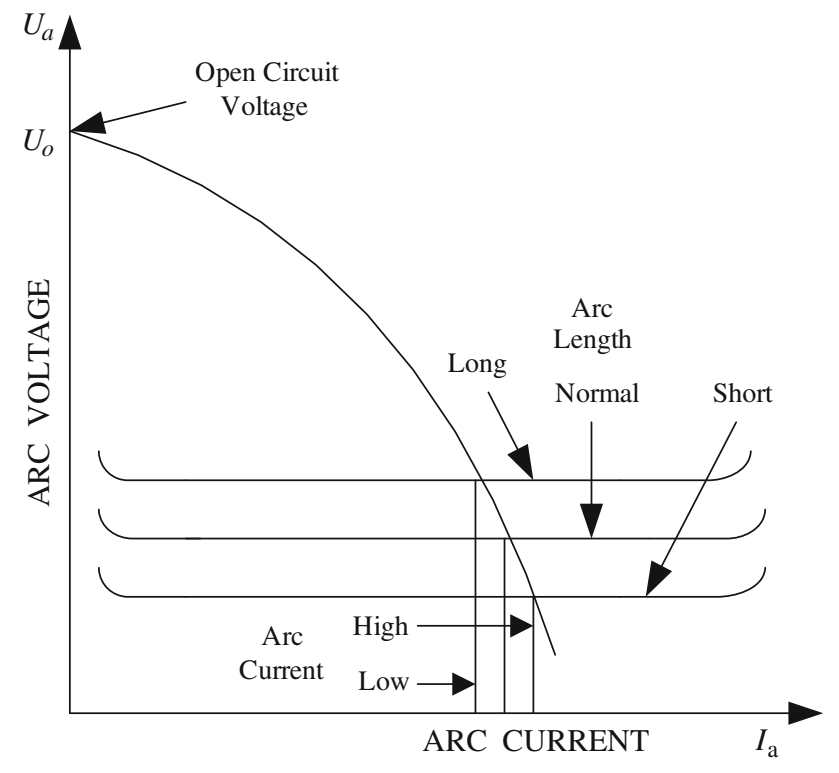

Fig. 1 Current output characteristics and arc static characteristics for SMAW process with constant current power supply

during welding. In the control system proposed in this study, the specified welding current is achieved by using an adaptive sliding mode controller to regulate the electrode feed rate based on a feedback signal obtained from a current sensor.

In arc welding, the desired constant arc length between the electrode and the workpiece can be maintained by appropriately modulating the feed rate of the electrode as it is consumed. Furthermore, to ensure the quality of the welding results, the specified system parameters, e.g. the arc current, $I_{\mathrm{a}}$, and the arc voltage, $V_{\mathrm{a}}$, must remain stable. To maintain a constant arc length, the electrode feed rate should equal the rate at which the electrode is consumed (the so-called melting rate), i.e.

$v_{\mathrm{fr}} \cong v_{\mathrm{mr}}$,

where $v_{\mathrm{fr}}$ is the electrode feed rate and $v_{\mathrm{mr}}$ the electrode melting rate. The electrode melting rate is a function of the arc current, $I_{\mathrm{a}}$, and the arc voltage, $V_{\mathrm{a}}$ (Bose 1986; Zheng and Hang 1987; Zhang and Liu 2007; Yang et al. 2007), i.e.

$v_{\mathrm{mr}}=k_{\mathrm{mr}} I_{\mathrm{a}}-k_{v} V_{\mathrm{a}}$,

where $k_{\mathrm{mr}}$ is the coefficient ratio of the melting rate to the arc current and $k_{v}$ the coefficient ratio of the melting rate to the arc voltage. Substituting Eq. 1 into Eq. 2, gives:

$I_{\mathrm{a}}=\frac{v_{\mathrm{fr}}}{k_{\mathrm{mr}}}+\frac{k_{v}}{k_{\mathrm{mr}}} V_{\mathrm{a}}$.

From Eq. 3, it is clear that in a constant electrode feed rate welding process, the welding current, $I_{\mathrm{a}}$, is dependent on both the electrode feed rate, $v_{\mathrm{fr}}$, and the arc voltage, $V_{\mathrm{a}}$. Equation 3 represents the relationship between the arc current and the arc voltage under the operating condition where the electrode feed rate equals the electrode melting rate. In other words, the operating points of $I_{\mathrm{a}}$ and $V_{\mathrm{a}}$ must always be maintained on the characteristic curve described by Eq. 3 if the welding process is to satisfy the condition $v_{\mathrm{mr}} \cong v_{\mathrm{fr}}$. Any deviation from this characteristic curve will inevitably result in an undesirable fluctuation of the arc length.

SMAW is classified as a long arc length welding process. In such processes, the choice of an appropriate electrode feed rate, $v_{\mathrm{fr}}$, depends more on the welding current, $I_{\mathrm{a}}$, than on the arc voltage, $V_{\mathrm{a}}$. Therefore, the current automatic SMAW control system can be simplified by regarding the arc voltage, $V_{\mathrm{a}}$, as a disturbance, $T_{\mathrm{d}}$, such that the arc current, $I_{\mathrm{a}}$, is virtually proportional to the electrode feed rate, $v_{\mathrm{fr}}$, i.e.

$I_{\mathrm{a}}=\frac{v_{\mathrm{fr}}}{k_{\mathrm{mr}}}$.

In the present study, the electrode holder is driven by a ball screw table actuated by a servomotor. This arrangement can be described by a first-order velocity dynamic system with a transfer function of the following form:

$\frac{V_{\mathrm{f}}(s)}{V(s)}=\frac{K_{m}}{J s+a}$,

where $K_{m}$ is the motor constant, $J$ the total inertia, and $a$ the viscous damping coefficient of the driving mechanism. The purpose of this driving mechanism is to control the electrode feed rate, $v_{\mathrm{fr}}$, such that it always equals the electrode melting rate, $v_{\mathrm{m}}$. The input to the driving mechanism is a control voltage, $V$, applied to the servomotor input terminal, while the output is the electrode feed rate, $v_{\mathrm{fr}}$. Combining Eqs. 4 and 5, and treating $V_{\mathrm{a}}$ in Eq. 3 as a disturbance, $T_{\mathrm{d}}$, the controlled nominal plant of the automatic welding process can be expressed as:

$G(s)=\frac{K_{m}}{k_{\mathrm{mr}}\left(J_{s}+a\right)}$.

Figure 2 presents a block diagram of the proposed automatic SMAW control system, comprising the system plant, the sliding mode controller and a current sensor. The reference input, $I_{\mathrm{r}}(s)$, is the command signal of the welding control system, while the arc current, $I_{\mathrm{a}}(s)$, is the controlled output variable. A feedback voltage signal, directly proportional to the magnitude of the output arc current, is obtained using a current sensor. The feedback signal is subtracted from the reference input, $I_{\mathrm{r}}(s)$, to obtain an error signal, $E(s)$, which is then input to the controller, $C(s)$. The controller responds by applying an appropriate output signal, $V(s)$, to the input terminal of the servomotor which actuates the electrode driving mechanism such that the desired arc length, and hence arc current, is maintained as the electrode is consumed.

The values of many of the unknown parameters in Eq. 6 cannot be obtained directly. Therefore, in designing a controller which satisfies all of the requirements, this study uses 


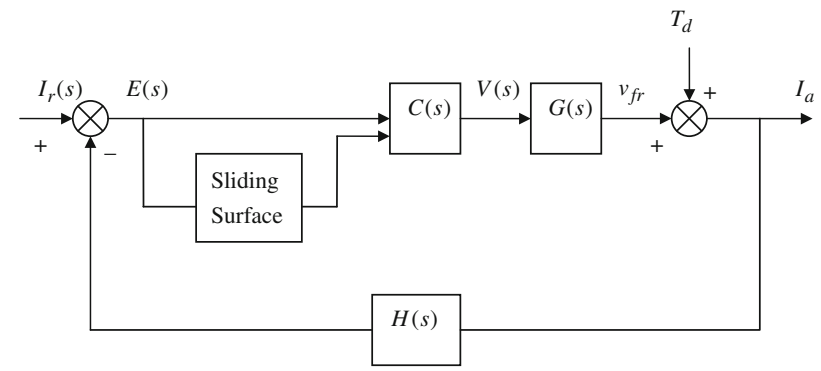

Fig. 2 Block diagram of closed-loop SMAW control system with adaptive sliding mode controller

a system identification technique to obtain their values. The best-fit values of the welding control system parameters are estimated using the ARX model in the "Matlab IDENTIFICATION Tool Box". The resulting nominal mathematical model of the SMAW control system is found to have the form:

$G(s)=\frac{1563000}{s^{2}+583.3 s+1575000}$.

The transfer function given in Eq. 7 is a second-order nominal transfer function with two poles located on the left half part of the s-plane.

\section{Adaptive siding mode arc current controller}

In the current sliding mode controller, the state-space representation, which includes the disturbance $T_{\mathrm{d}}$, is expressed as:

$$
\begin{aligned}
\dot{x} & =A x+B u \\
y & =C x+T_{\mathrm{d}}, \\
A & =\left[\begin{array}{cc}
0 & 1 \\
-a_{0} & -a_{1}
\end{array}\right], \quad B=\left[\begin{array}{l}
1 \\
0
\end{array}\right], \quad C=\left[\begin{array}{ll}
c & 0
\end{array}\right]
\end{aligned}
$$

where $a_{1}=583.3, a_{0}=1575000$ and $c=1563000, x \in R^{2}$ is the state vector, $y$ is the scalar output variable, and $u$ is the scalar control input.

For the present regulation problem, the error, $e(t)$, is defined as $e(t)=e_{1}=r-y(t)$, where $r$ denotes the reference command input and $y$ is the arc current, which is the only measurable variable in the welding system. Substituting $e(t)$ into Eq. 8, the error dynamic equation is given by:

$$
\begin{aligned}
& \dot{e}_{1}=e_{2}, \\
& \dot{e}_{2}=a_{0}\left(r-e_{1}\right)-a_{1} e_{2}-c u+\bar{e},
\end{aligned}
$$

where $\bar{e}=-a_{0} T_{\mathrm{d}}-a_{1} \dot{T}_{\mathrm{d}}-\ddot{T}_{\mathrm{d}}$ and is bounded. Let the sliding surface be defined as:

$\mathrm{s}(\mathrm{t})=\dot{e}(t)+\lambda \mathrm{e}(t)$
Then, a sliding mode arc current controller which satisfies the hitting condition $\lim _{t \rightarrow 0} s \dot{s}<0$ can be obtained as (Li 1991):

$u=\frac{1}{c}\left[u_{\mathrm{eq}}+\bar{\beta} \operatorname{sgn}(s(t))\right]$,

where $u_{\mathrm{eq}}=a_{0}(r-e)+\left(a_{1}-\lambda\right) \dot{e}$ is the equivalent control, and sgn (.)is a sign function with the form:

$\operatorname{sgn}(s(t))=\left\{\begin{array}{ll}+1, & \text { if } s(t)>0 \\ -1, & \text { if } s(t)<0\end{array}\right.$,

In Eq. $12, \bar{\beta}$ is the upper bound of the disturbance, i.e. $|\bar{e}| \leqslant \bar{\beta}$. The sliding mode controller in Eq. 12 satisfies the hitting condition only if $|\bar{e}| \leqslant \bar{\beta}$. Under this condition, the sliding mode occurs and the welding control system given in Eq. 10 can be expected to be stable.

In implementing the proposed control scheme, parameter $\bar{\beta}$ in Eq. 12 must be determined. To meet the hitting condition, its value must be greater than the upper bound of the system disturbance, $\bar{e}$. However, estimating the disturbance which may exist in the welding system is difficult, and hence it is impossible to identify the upper bound $|\bar{e}|$ in Eq. 10 precisely in advance. Therefore, this study develops an adaptive law for the proposed sliding mode controller such that the upper bound of the disturbance can be accurately estimated.

In practice, an ideal sliding mode cannot exist since this would imply that the control commutes at an infinite frequency. When switching imperfections exist, e.g. switching time delays and small time constants in the actuators, the resulting discontinuity in the feedback control produces a particular dynamic behavior known as "chattering" in the vicinity of the surface.

This phenomenon is undesirable since, even if it is filtered at the output of the process, it may excite unmodeled high frequency modes, which degrade the performance of the system and may even lead to instability (Heck 1991). Chattering can also lead to high wear of any moving mechanical parts in the system and to high heat losses in electrical power circuits. Therefore, various procedures have been designed to eliminate, or at least reduce, the chattering effect. One such procedure consists in regulation scheme in some neighborhood of the switching surface which, in the simplest case, merely consists of replacing the signum function by a continuous approximation with a high gain in the boundary layer, e.g. the signum function (Slotine 1984) or the saturation function in which sat (.) is defined as:

sat $(S, \varepsilon)=\left\{\begin{array}{cc}1 & S>\varepsilon \\ \frac{S}{\varepsilon} & -\varepsilon \leq S \leq \varepsilon \\ -1 & S<\varepsilon\end{array}\right.$

However, although this saturation function can eliminate chattering, this study increases the robustness of the sliding 


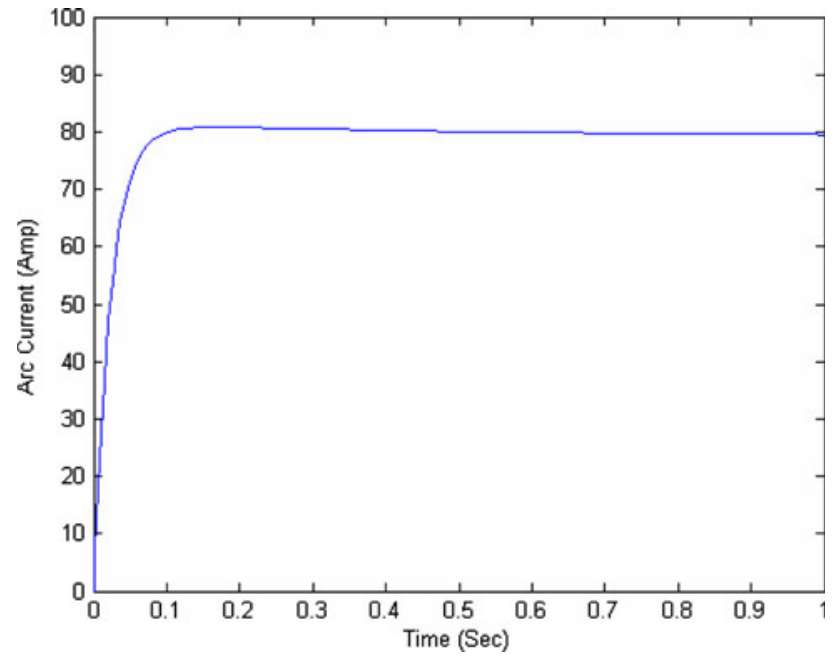

Fig. 3 Simulation of adaptive sliding mode controller using $80 \mathrm{Amp}$ reference command input

mode by employing the following modified sliding function (Shyu and Liu 1996; Spurgeon and Patton 1999);

ssat $(S, \varepsilon)=\left\{\begin{array}{cc}1 & S>\varepsilon \\ \frac{S}{\varepsilon} & -\varepsilon \leq S \leq \varepsilon \quad \varepsilon=\alpha+\beta\|Z\|_{2} \\ -1 & S<-\varepsilon\end{array}\right.$

where $\|Z\|_{2}=\sqrt{(\lambda e)^{2}+(\dot{e})^{2}}, 0<\beta<1$, and $\alpha$ and $\beta$ are user-defined variable parameters which indicate the minimum and maximum values, respectively, of the sliding layer $\varepsilon$ in the saturation function. From Eq. 15, it is clear that the saturation function ssat $(S, \varepsilon)$ eliminates chattering in the neighborhood of the sliding surface or operation point and minimizes the steady error.

Figure 3 presents the simulation results obtained for the proposed automatic SMAW control system with an adaptive sliding mode controller for an $80 \mathrm{Amp}$ step input reference command. Figure 4 shows the corresponding sliding surface.

\section{Experimental equipments and results}

Figures 5 and 6 present a schematic of the proposed automatic SMAW control system and a photograph of the corresponding experimental setup. As shown, the welding system includes a PC-based controller (586 PC Computer), a servomotor-actuated welding robot, a current sensor and a welding power source. During the welding operation, the actual welding current is measured by the current sensor, converted to a digital signal by an A/D converter, and supplied to the PC-based controller as a feedback signal. The adaptive sliding mode control algorithm processes the feedback signal and outputs an appropriate control signal through a D/A converter and an amplifier to the input terminal of the $\mathrm{AC}$

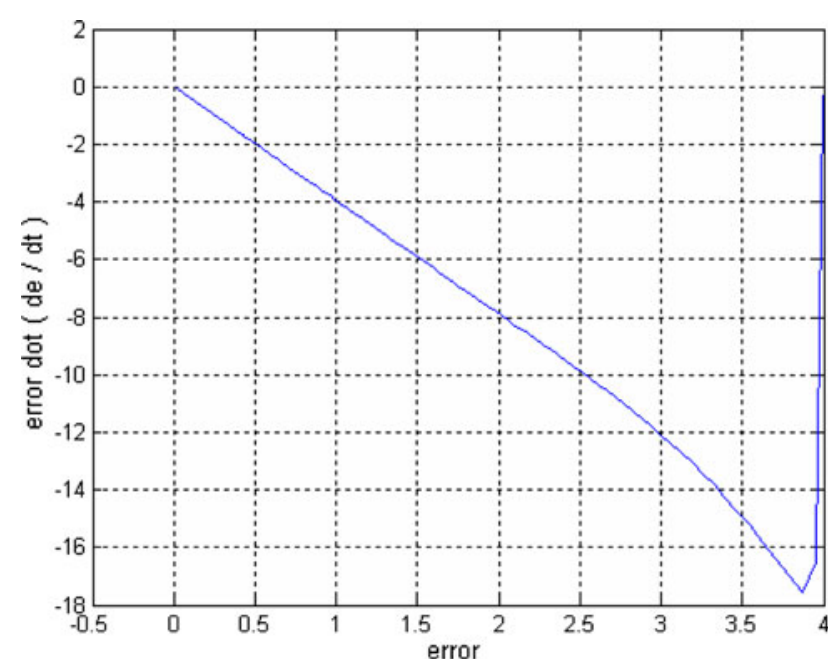

Fig. 4 Error State in Fig. 3

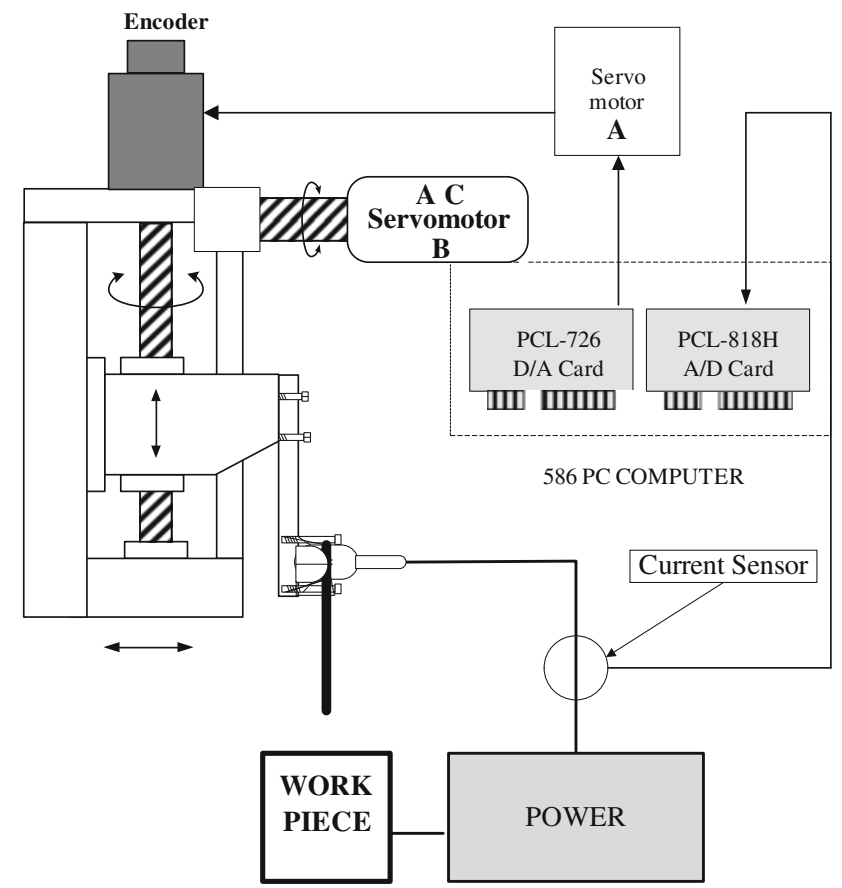

Fig. 5 Structure of automatic SMAW control system

servomotor (labeled A in Fig. 5), which then regulates the electrode feed rate accordingly. In the current experimental setup, the welding current is measured using an LEM HAS 200 SI Hall-Effect current sensor, with a peak current and rms rated voltage of $200 \mathrm{Amp}$ and $50 \mathrm{~V}$, respectively. The welding current command is set to $80 \mathrm{Amp}$ and welding is performed using an E4313 electrode with a core wire diameter of $2.6 \mathrm{~mm}$. During welding, the electrode is maintained in a vertical position relative to the welding path and is driven by a second $\mathrm{AC}$ servomotor (labeled $\mathrm{B}$ in Fig. 5). 


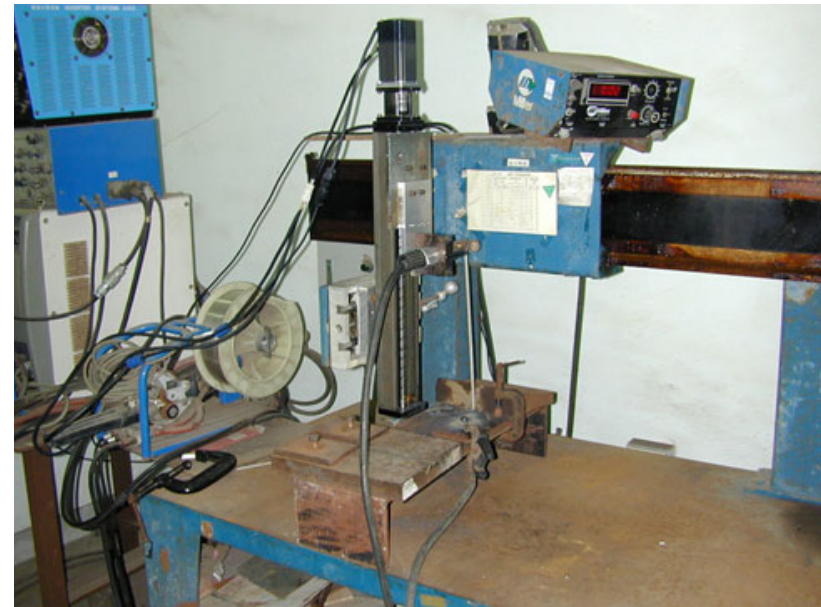

Fig. 6 Photograph of automatic SMAW control system

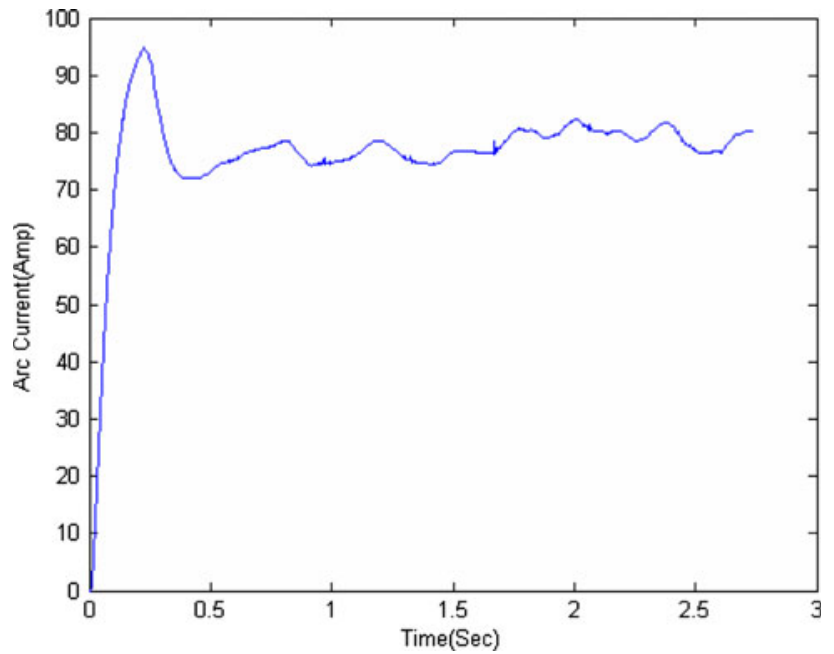

Fig. 7 Experimental arc current output response with adaptive sliding mode controller using $80 \mathrm{Amp}$ step reference command input

Figure 7 plots the experimental results obtained for the arc current during an automatic SMAW process performed under the control of the adaptive sliding mode controller with an 80 Amp step input reference command. As shown, a short circuit arc current of approximately $160 \mathrm{Amp}$ is generated when the electrode momentarily makes contact with the base metal during the arc initiation process ( 0 to 0.7 seconds). Figure 8 shows the corresponding experimental sliding surface results. Meanwhile, Fig. 9 presents a photograph of the results obtained in an automatic plate position welding experiment using an $80 \mathrm{Amp}$ reference command input. It is seen that the weld surface is characterized by uniform ripple beads, which is indicative of an acceptable welding performance. Figures 10 and 11 show the arc current response and the corresponding welding results obtained from a tuning PID by GA controller. Comparing Figs. 9 and 11, the improved welding bead uniformity and the reduced spatter generation

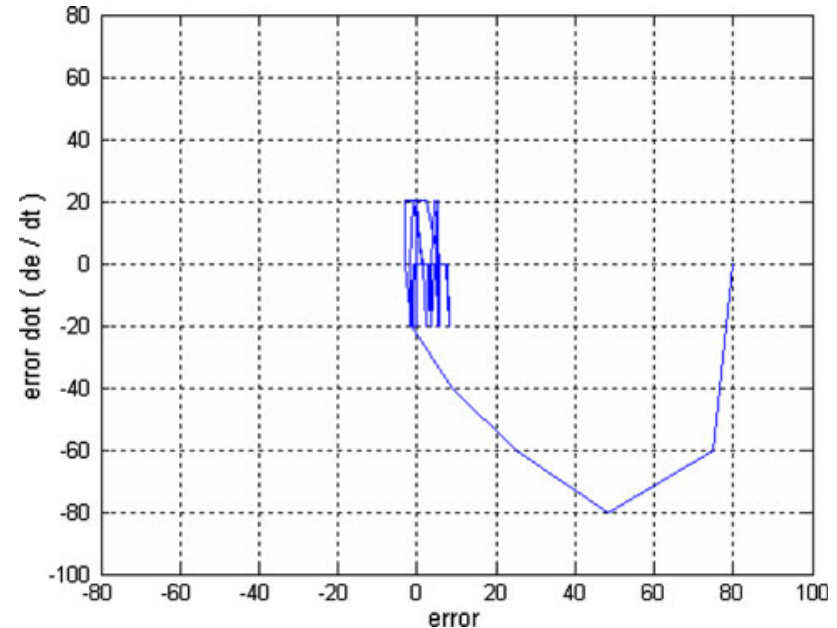

Fig. 8 Sliding surface in Fig. 9

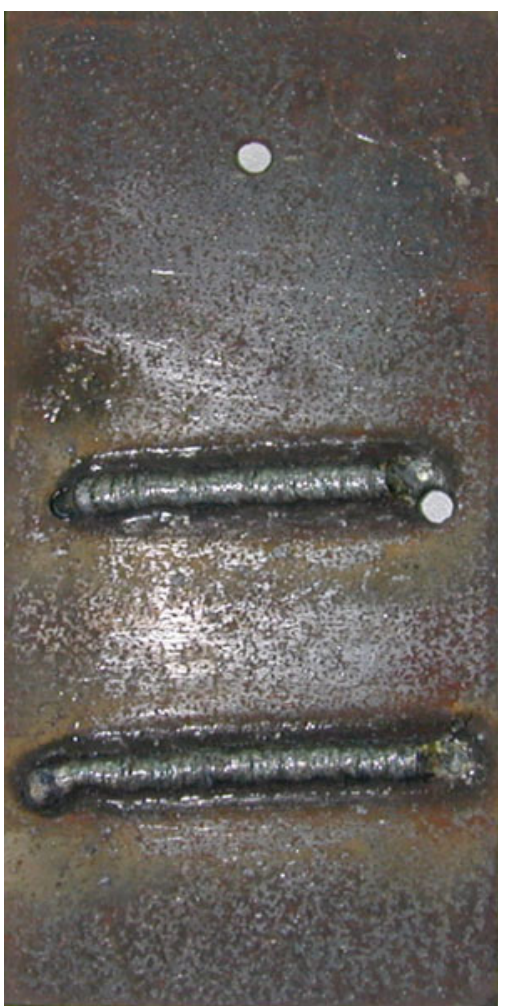

Fig. 9 Photograph of the plate position welding experiment

in the former provide clear evidence of the superior welding performance obtained under the proposed welding control scheme.

\section{Conclusion}

This study has successfully developed an adaptive sliding mode controller for an automatic alternating current SMAW system. A mathematical model of the automatic welding 


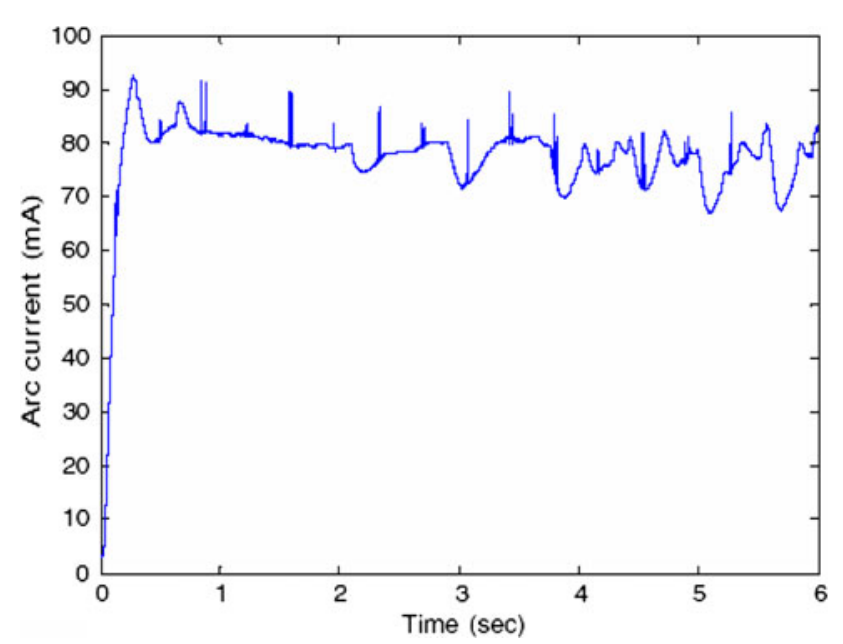

Fig. 10 Arc current output for tuning PID by GA controller

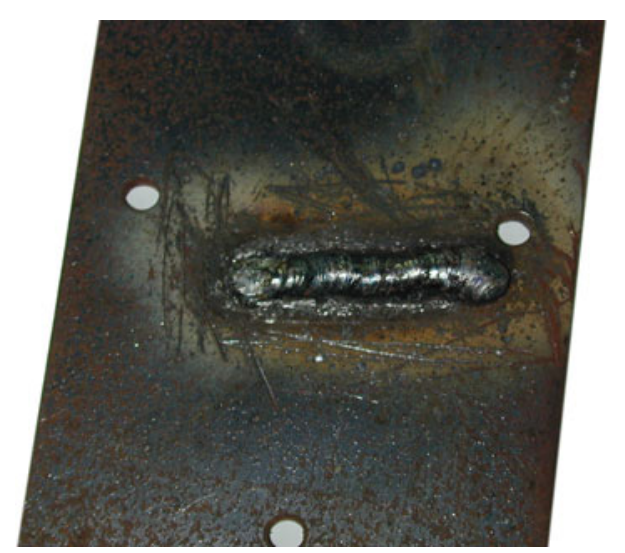

Fig. 11 Photograph of welding result in Fig. 9

control system has been constructed by analyzing physical laws and utilizing a system identification technique. In the proposed approach, the adaptive sliding mode controller determines an appropriate output signal by evaluating an error signal (and its derivative) provided by a current sensor. The output signal is applied to the input terminal of an $\mathrm{AC}$ servomotor, which responds by driving the electrode feed rate mechanism such that the required arc length, and hence arc current, are maintained. The experimental and numerical results have demonstrated that the adaptive sliding mode controller developed in this study ensures a high quality SMAW result and enables the realization of an automatic shielded metal arc welding process.

Open Access This article is distributed under the terms of the Creative Commons Attribution Noncommercial License which permits any noncommercial use, distribution, and reproduction in any medium, provided the original author(s) and source are credited.

\section{References}

Abdelhameed, M. M. (2005). Enhancement of sliding mode controller by fuzzy logic with application to robotic manipulators. Mechatronics, 15(4), 439-458.

Abdelrahman, M. (1998). Feedback linearization control of current and arc length in GMAW systems. IEEE International Conference, American Control Conference, 3, 1757-1761.

Baldwin, T. L., Hogans, T., Henry, S. D., Renovich, F., Latkovic, P. T. (2005). Reactive-power compensation for voltage control at resistance welders. IEEE Transactions on Industry Applications, 41(6), $1485-1492$.

Bose, B. K. (1986). Power electronics and AC drives. Englewood Cliffs, NJ, USA: Prentice-Hall, Inc.

Chae, Y. M., Choe, G. H., et al. (1999). A new instantaneous output current control method for inverter arc welding machine. IEEE PRCS' 99 Records, 1, 521-528.

Chung, T. L., Bui, T. H., Nguyen, T. T., Kim, S. B. (2004). Sliding mode control of two-wheeled welding mobile robot for tracking smooth curved welding path. KSME International Journal, 18(7), 1094-1106.

Decarlo, R. A., Zak, S. H., Matthews, G. P. (1998). Variable Structure Control of Nonlinear Multivariable System: A Tutorial. Proceedings of the IEEE, 76(3), 212-232.

Heck, B. (1991). Sliding mode control for singularly perturbed systems. International Journal of Control, 53, 985-1001.

Hung, J. Y., Gao, W. B., Hung, J. C. (1993). Variable structure control: A survey. IEEE Transactions on Industrial Electronics 40, 402-422.

Li, S. (1991). Applied nonlinear control. Englewood Cliffs, NJ, USA: Prentice-Hall, Inc.

Lu, W., Zhang, Y. M., Lin, W. Y. (2004). Nonlinear interval model control of quasi-keyhole arc welding process. Automatica, 40(5), 805-813.

Modenesi, P. J., Reis, R. I. (2007). A model for melting rate phenomena in GMA welding. Journal of Materials Processing Technology, 189(1-3), 199-205.

Ngo, M. D., Duy, V. H., Phuong, N. T. (2007). Development of digital gas metal arc welding system. Journal of Materials Processing Technology, 189 (1-3), 384-391.

Shyu, K. K., Liu, C. Y. (1996). Variable structure controller design for robust tracking and model following. Journal of Guidance, Control, and Dynamics, 19(6), 1395-1397.

Shyu, K. K., Tsai, Y. W., Yung, C. F. (1992). A modified variable structure controller. Automatica, 28(6), 1209-1213.

Slotine, J.-J. E. (1984). Sliding controller design for nonlinear systems. International Journal of Control, 40(2), 421-434.

Smith, D. (1989). Welding skills and technology. New York: McGrawHill Book Co.

Spurgeon, S. K., Patton, R. J. (1999). Robust variable structure control of model reference system. IEE Proceedings: Control Theory and Applications, Pt.D., 137(6), 341-348.

Verdelho, P., Silva, M. P., Margato, E., Esteves, J. (1998). An electronic welder control circuit. IEEE International Conference, Industrial Electronics Society, 2, 612-617.

Wang, J., Rad, A. B., Chan, P. T. (2001a). Indirect adaptive fuzzy sliding mode control: Part I: Fuzzy switching. Fuzzy Set and Systems, 122, 21-30.

Wang, J., Rad, A. B., Chan, P. T. (2001b). Indirect adaptive fuzzy sliding mode control: Part II: Parameter projection and supervisory control. Fuzzy Set and Systems, 122, 31-43.

Yamamoto, H., et al. (1990). The development of welding control system for spatter reduction. Welding International, 14(5), 398-403.

Yang, S. M., Cho, M. H., Lee, H. Y., Cho, T. D. (2007). Weld line detection and process control for welding automation. Measurement Science and Technology, 18(3), 819-826. 
Zhang, Y. M., Liu, Y. C. (2007). Control of dynamic keyhole welding process. Automatica, 43(5), 876-884.

Zhang, J., Walcott, B. L. (2006). Adaptive interval model control of arc welding process. IEEE Transactions on Control Systems Technology, 14(6), 1127-1134.
Zhang,Y. M., Liguo, E., Walcott, B. L. (1998). Interval model based control of gas metal arc welding. IEEE International Conference, American Control Conference, 3, 1752-1756.

Zheng, Y. T., Hang, S. S. (1987). Arc welding power supply. 2nd ed. Peking: Machine Industrial Book Co. 